\title{
Expectativa de vida e causas de morte em cães na área metropolitana de São Paulo (Brasil)
}

\author{
Life expectation and causes of death in dogs in the metropolitan area of \\ São Paulo (Brazil)
}

\author{
Henri Donnarumma Levy Bentubo ${ }^{\mathrm{I}}$ Maurício Angelo Tomaz ${ }^{\mathrm{II}}$ \\ Eduardo Fernandes Bondan ${ }^{\mathrm{III}}$ Maria Anete Lallo ${ }^{\mathrm{IV*}}$
}

RESUMO

Com o objetivo de avaliar a expectativa de vida dos cães na área metropolitana de São Paulo e as causas relacionadas com a morte destes, foram analisados dados correspondentes a 2.011 animais provenientes de um hospital veterinário universitário, de clínicas particulares, de canis e de proprietários particulares. A idade mediana de sobrevivência dos animais foi de 36 meses. Os animais de porte médio, grande e gigante tiveram maior longevidade que os cães de porte pequeno. As fêmeas viveram mais que os machos e os animais castrados viveram mais que os não-castrados. Não houve diferença na expectativa de vida entre os animais de raça pura e os animais sem raça definida. Constatou-se que as causas mais importantes de mortalidade foram, em ordem decrescente de ocorrência, as doenças infecciosas, as neoplasias $e$ os traumas. Pode-se concluir que a expectativa de vida dos cães foi menor que a observada na literatura internacional $e$ que as doenças infecciosas constituem a principal causa de óbito.

Palavras-chave: cães, expectativa de vida, longevidade, causa mortis.

\section{ABSTRACT}

In order to evaluate the canine life expectation in the metropolitan area of São Paulo, as well as the causes of death of these animals, data related to 2,011 dogs attended at a University Veterinary Hospital or collected from veterinary clinics, kennels and private owners were analyzed. It was observed that the median age of the dogs at death due to all causes was 36 months old. Dogs of medium, large and giant breeds had longer longevity than the small ones. Female and neutered dogs lived longer than male and intact dogs. There was no difference in life expectation related to the fact that the animal was from a pure breed or not. The most important causes of mortality were, in decrescent order of occurrence, infeccious diseases, neoplasms and traumatic injuries. Canine life expectation found in this survey was shorter than that observed in other countries and infeccious diseases constitute the major cause of death.

Key words: dogs, life expectation, longevity, death cause.

\section{INTRODUÇÃO}

Os animais de estimação, em especial cães e gatos, representam companhia para muitas pessoas e podem também contribuir com o desenvolvimento físico, social e emocional das crianças e com o bemestar de seus proprietários, em particular de indivíduos idosos. Além dos reconhecidos benefícios psíquicos, estudos clínicos revelam normalização da freqüência cardíaca e dos níveis de pressão arterial nos indivíduos que possuem animais de estimação (BERZINS, 2000; PATRONEK et al., 1997; WONG et al., 1999).

Os animais de estimação são criados, muitas vezes, de acordo com a rotina de vida dos seres humanos, geralmente, cometendo-se o erro de incorporar maus hábitos ao seu cotidiano, privandoos de sua vida instintivamente saudável e de seus hábitos naturais. Tais alterações acabam por se refletir diretamente na sua expectativa de vida (BERZINS, 2000; WONG et al., 1999).

A idade é definida como um processo biológico complexo, que resulta na redução progressiva da capacidade de um indivíduo manter a homeostasia sob estresses fisiológicos, diminuindo,

IPrograma de Pós-graduação em Microbiologia, Instituto de Ciências Biomédicas, Universidade de São Paulo (USP), São Paulo, Brasil.

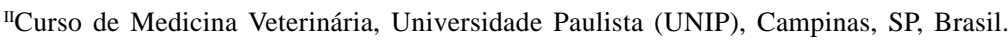

III Universidade Paulista (UNIP), Universidade Cruzeiro do Sul (Unicsul), São Paulo, SP, Brasil.

IVUniversidade Paulista (UNIP), Universidade Metodista de São Paulo (UMESP), Unicsul. Rua Caconde 125/51, 01425-011, São Paulo, SP, Brasil. E-mail: bondan@uol.com.br. *Autor para correspondência. 
assim, a viabilidade desse ser, aumentando a sua vulnerabilidade a doenças e levando-o, finalmente, à morte (FRIES \& CRAPO, 1981; GOLDSTON \& HOSKINS, 1999).

Qualquer organismo, desde a concepção até a morte passa pelas fases de desenvolvimento, puberdade, chegando então à maturidade, também chamada de fase de estabilização, e, por fim, alcançando a fase de envelhecimento ou declínio (PAPALÉO NETTO, 2002). O tempo médio de sobrevivência de uma população é um reflexo de seus potenciais genômico e fenotípico de adaptação, além de outros fatores que também interferem em graus variáveis com o processo de envelhecimento e morte (PAPALÉO NETTO, 2002; WALFORD, 1985).

O século passado foi marcado, na medicina humana, pela explosão de medidas preventivas visando a prolongar a vida. Em populações nas quais tais medidas inexistem ou são precárias, seus indivíduos estão mais expostos aos riscos ambientais, e a possibilidade de morte estará sempre presente em qualquer período da vida. Nas populações mais protegidas, que habitam áreas nas quais o meio ambiente se acha sob controle, a morte pode ser adiada até o limite biológico da existência, quando a longevidade esperada é alcançada (PAPALÉO NETTO, 2002). Tais medidas somente podem ser aplicadas quando os índices de mortalidade e morbidade são conhecidos e os fatores de risco bem estabelecidos. Infelizmente, estimativas de longevidade em cães foram descritas em poucos países, tais como nos Estados Unidos, com idade média de sobrevivência de 9,9 anos (BRONSON, 1982); na Suécia, com 10 anos (BONNETT et al., 1997); no Japão, com 8,3 anos (HAYASHIDANI et al., 1998); na Inglaterra, com 11 anos (MICHELL, 1999) e na Dinamarca, com 10 anos de idade (PROSCHOWSKY et al., 2003). Tal fato se explica pela grande dificuldade de obtenção de dados populacionais em geral, devido à variedade de raças e de condições ambientais (BONNETT et al., 1997).

Estudos de longevidade e de avaliação dos motivos que levam à eutanásia têm sido realizados, mediante utilização de dados obtidos em questionários (MICHELL, 1999), serviços de necropsia (BRONSON, 1982), companhias de seguros (BONNETT et al., 1997) e cemitérios de animais (HAYASHIDANI et al., 1998). Um estudo realizado pela American Veterinary Medical Association, nos Estados Unidos, revelou que 41,7\% da população canina tinha seis anos ou mais e que 13,9\% possuía 11 anos ou mais (GOLDSTON \& HOSKINS, 1999). Observou-se a longevidade e a morbidade canina num período de dez anos em sete raças gigantes e em sete raças pequenas, evidenciando uma sobrevida maior dos cães de pequeno porte em relação aos gigantes (DEEB \& WOLF, 1994).

O conhecimento das causas mais comuns de doenças e óbitos em cães pode auxiliar no estabelecimento e na adoção de medidas preventivas prioritárias e na educação dos proprietários. Atenção e dedicação por parte de proprietários e médicos veterinários são necessárias para que se possa elevar o tempo de sobrevivência dos cães. Para as populações caninas nas quais as medidas preventivas de controle dos fatores que interferem com o envelhecimento são adequadas, há um aumento na sobrevida média das mesmas (FRIES \& CRAPO, 1981; GOLDSTON \& HOSKINS, 1999).

Acredita-se que, na cidade de São Paulo, existam cerca de 1.490 .412 cães e que a média de animais por residência seja de 1,53 (PARANHOS, 2002). Entretanto, não existem trabalhos sobre a expectativa de vida da população canina ou sobre as causas de morte desses animais neste município. Neste contexto, o objetivo deste trabalho foi o de determinar a idade de morte de cães na região de São Paulo, assim como identificar suas principais causas.

\section{MATERIAL E MÉTODOS}

Com a finalidade de compor uma amostra que contemplasse diferentes estratos populacionais, foram coletados dados procedentes dos seguintes grupos: cães atendidos por um Hospital Veterinário Universitário ( $\mathrm{n}=500)$, os atendidos em 11 clínicas veterinárias particulares de São Paulo e região (n = 900), aqueles criados em canis particulares e de pessoas, selecionadas aleatoriamente, que concordaram em participar da pesquisa $(n=611)$. Nenhuma restrição foi feita quanto à idade na data do óbito do animal, sendo compreendidas todas as faixas etárias. Foram incluídas informações sobre cães que morreram entre 1995 e 2005.

Para todos os animais, foram pesquisados dados sobre raça, idade na data de ocorrência do óbito (registrada em meses), sexo, se o animal era ou não castrado, causa da morte e ocorrência de morte natural ou por eutanásia.

No caso dos animais registrados no Hospital Veterinário ou dos atendidos em clínicas veterinárias particulares, os dados foram obtidos pela pesquisa de seus prontuários e compilados em tabelas. Nestes casos, foi considerada a causa de morte documentada nos prontuários pelo médico veterinário responsável e, quando possível, a mesma foi confirmada pelo estudo anatomopatológico. Para os demais cães, um questionário foi respondido pelo próprio proprietário, que recebeu instruções quanto ao seu preenchimento. 
No caso dos dados colhidos por meio de questionários, a causa de morte do animal foi relatada pelos proprietários, não sendo validada por médicos veterinários (n=611).

Para facilitar a análise estatística e a interpretação dos resultados, os animais foram separados de acordo com a causa de morte nos seguintes grupos: traumatismos; doenças infecciosas (englobando aquelas causadas por bactérias, vírus e fungos); doenças parasitárias; intoxicações (tanto as de origem acidental quanto as criminosas ou medicamentosas); neoplasias; senilidade (mortes naturais pelo envelhecimento); doenças metabólicas (referentes às enfermidades que interferem diretamente no metabolismo global do organismo, incluindo as insuficiências renal e hepática, entre outras); doenças cardiocirculatórias (abrangendo todas as doenças determinantes de insuficiência circulatória); doenças neurológicas; doenças congênitas e/ou hereditárias e, finalmente, as ortopédicas (nas quais foram incluídas as doenças osteoarticulares, excluindo-se as fraturas que ficaram no grupo dos traumatismos).

O animais também foram divididos segundo seu porte físico, levando-se em consideração seu peso em quilogramas, independentemente da raça ou idade, em porte pequeno (para animais com peso igual ou inferior a 9kg); porte médio (para os animais entre 9,5kg e $23 \mathrm{~kg}$ ); porte grande (para aqueles com peso entre 23,5kg e 40kg); e porte gigante (para animais com mais de 40,5kg), segundo classificação proposta por GOLDSTON \& HOSKINS (1999).

Primeiramente realizou-se a análise exploratória dos dados pela prova estatística de Shapiro-Wilk e a inspeção visual do gráfico de quantis (qqplot). A partir desta análise, observou-se que a idade, em função das variáveis independentes (gênero, castração, porte e causa padrão do óbito), não seguia uma distribuição normal, sendo então utilizada como medida de posição a mediana e como estimador da variabilidade dos dados o intervalo interquartil.

Para as variáveis raça, gênero e castração, foram aplicadas a prova estatística de Mann-Whitney U e a de Kruskal-Wallis para observar a significância da diferença na idade dos níveis das variáveis causa de óbito e porte. Quando se obtinham diferenças que atingiam o nível de significância estatística $(\alpha)$, foi aplicada a prova de Mann-Whitney U, com correção de $\alpha$ dada por Bonferroni, para definir em quais pares havia de fato diferenças. A significância estatística foi aceita em $\mathrm{a}=0,05$, sendo que todo o processamento estatístico foi realizado no software $\mathrm{R}$ versão 2.2.1 ( $\mathrm{R}$ Development Core Team, 2005).

\section{RESULTADOS E DISCUSSÃO}

Houve uma distribuição uniforme dos dados de acordo com o gênero dos animais (49,53\% fêmeas e $50,47 \%$ machos). Somente $3,53 \%$ correspondiam a animais castrados (machos ou fêmeas) e 36,05\% eram de raça não-definida.

Em relação ao porte, verificou-se que $11,74 \%$ dos animais tinham porte indeterminado devido à falta de dados de seu peso. Entre os animais com peso definido, 38,59\% eram de pequeno porte e $22,87 \%$ eram de médio porte, já os cães de grande porte representavam $20,49 \%$ e $6,32 \%$ foram classificados como de porte gigante.

A idade mediana de vida dos animais neste trabalho foi de 36 meses (considerando intervalo interquartil: quartil 1- quartil 3), sendo, portanto, muito inferior aos resultados encontrados por PROSCHOWSKY et al. (2003) na Dinamarca e BRONSON (1982) nos Estados Unidos, que foram, respectivamente, de 120 e 117 meses de idade em cães de raças puras ou mistas. Na Inglaterra, MICHELL (1999) registrou idade de sobrevida de 132 meses em animais de raças inglesas e, no Japão, HAYASHIDANI et al. (1998) verificaram que a idade de morte de cães enterrados num cemitério de animais foi de 99 meses. Portanto, este resultado mostra que a expectativa de vida de cães na região metropolitana de São Paulo foi muito baixa (apenas 36 meses de vida), refletindo a necessidade de se investigar outras regiões e se pensar em medidas gerais para o aumento da sobrevida dos animais de estimação em nosso país.

A sobrevivência dos animais em função de seu gênero não tem revelado grande importância (BRONSON, 1982; MICHELL, 1999), no entanto, neste trabalho observou-se maior longevidade das fêmeas em relação aos machos (Tabela 1), discordando dos dados observados na literatura. Os machos abandonam suas residências em busca de acasalamentos, estando mais expostos às condições ambientais, que colocam sua vida em risco; por sua vez, as fêmeas permanecem mais tempo isoladas naépoca do puerpério(BERZINS, 2000). Estas características relacionadas com a reprodução podem explicar a maior longevidade de fêmeas retratada neste estudo, especialmente considerando-se que a maioria dos animais não era castrada.

Em estudo anterior, já foi observado que as fêmeas castradas $(n=720)$ apresentam maior taxa de sobrevivência que os machos castrados ( $n=291)$ e que todos os cães não-castrados ( $\mathrm{n}=2110)$ MICHELL (1999). No presente trabalho, observou-se que os animais castrados $(n=71)$ viveram mais que os animais nãocastrados $(\mathrm{n}=1940)$ (Tabela 1), não se identificando 
Tabela 1 - Descrição e comparação da idade de óbito em cães do município de São Paulo e relação a gênero ou castração.

\begin{tabular}{lcc}
\hline Variável & \multicolumn{2}{c}{ Idade de óbito (meses) } \\
& Mediana (IQR) & [quartil 1; quartil 3] \\
\hline Raça & $36,0(102,0)$ & {$[6,0 ; 108,0]$} \\
Definida $(\mathrm{n}=1286)$ & $36,0(112,0)$ & {$[8,0 ; 120,0]$} \\
Não-definida $(\mathrm{n}=725)$ & & \\
Gênero & $48,0(112,0)$ & {$[8,0 ; 120,0]^{*}$} \\
Feminino $(\mathrm{n}=996)$ & $29,0(93,0)$ & {$[7,0 ; 100,0]$} \\
Masculino $(\mathrm{n}=1015)$ & & {$[52,0 ; 157,5] \dagger$} \\
Castrado & $108,0(105,5)$ & {$[7,0 ; 108,0]$} \\
Sim (n= 71) & $36,0(101,0)$ & \\
Não $(\mathrm{n}=1940)$ &
\end{tabular}

IQR:intervalo interquartil.

*Indica diferença estatisticamente significante, $\mathrm{P}=0,0055$; em relação ao gênero masculino.

${ }^{\dagger}$ Indica diferença estatisticamente significante, $\mathrm{P}=0,0001$; em relação aos cães não-castrados.

diferenças entre os gêneros. Esses resultados devem ser interpretados com cuidado, já que o número de animais castrados no presente estudo foi muito pequeno, em relação a outros levantamentos, revelando que a castração ainda é um procedimento pouco utilizado e que a longevidade deste grupo deve ser melhor analisada em futuros trabalhos.

O mito de que animais sem raça definida (SRD) vivem mais que os de raça pura já foi derrubado por BRONSON (1982) e MICHELL (1999)e, mais uma vez, de acordo com os resultados obtidos na presente investigação, observou-se que não houve diferença significativa na longevidade entre os mesmos (Tabela 1).

Existe uma teoria de envelhecimento que relaciona a sobrevivência dos animais ao seu número debatimentos cardíacos (GOLDSTON\& HOSKINS, 1999). Segundo a mesma, as espécies com alta freqüência cardíaca apresentam menor sobrevivência. Neste sentido, alguns autores têm procurado avaliar a influência do tamanho dos cães de diferentes raças na expectativa de vida. Os resultados da presente investigação reforçam esta teoria, já que animais de pequeno porte (Tabela 2) sobreviveram menos que os animais de porte médio, grande e gigantes. Entretanto, discorda dos dados observados por outros autores (ANDERSEN \& ROSENBLATT, 1965; DEEB \& WOLF, 1994), que relataram maior sobrevivência em cães de pequeno porte.

A base biológica do envelhecimento está fundamentada em fatores genéticos, principalmente naqueles que afetam o reparo somático, a capacidade de resposta ao estresse, a resposta imune e a suscetibilidade às doenças, a supressão de tumores, o estresse oxidativo, a falha no reparo do DNA e a reativação de genes normalmente inativados (MICHELL, 1999). Muitas destas teorias devem ser avaliadas para as diferentes raças, uma vez que a análise dos animais somente pelo seu porte físico tem se mostrado insuficiente e ineficaz (HAYFLICK, 1985; GOLDSTON \& HOSKINS, 1999; WALFORD, 1985).

A principal causa de morte canina relatada em diferentes estudos é o câncer (BRONSON, 1982; MICHELL, 1999; PROSCHOWSKY et al., 2003). Nesta pesquisa, as neoplasias constituíram uma importante causa de óbito (Tabela 3), porém ficou em segundo lugar. Sabe-se que os tumores são mais prevalecentes em animais bem idosos e, como a taxa de sobrevivência dos cães foi inferior às observadas por outros autores, essa pode ser a justificativa de sua colocação em segundo lugar.

As doenças infecciosas destacaram-se como principal causa de morte (Tabela 3), tratando-se de um fator de risco bem caracterizado, que reduz a expectativa de vida dos cães no Brasil. A idade mediana de vida foi de 12 meses para cães que morreram por agentes infecciosos (em especial, pelos vírus da cinomose, da parvovirose, da coronavirose). Muitas destas doenças podem ser controladas por programas simples de imunoprofilaxia, que deveriam ser iniciados nas primeiras semanas de vida. Entretanto, em decorrência da falta de conhecimento, das dificuldades econômicas da população e da negligência dos proprietários, tais enfermidades acabam ainda por se constituir num fator determinante de mortalidade. Outro achado importante é que as doenças infecciosas constituíram a principal causa de morte, independentemente da raça, mostrando que programas de prevenção não são realizados a contento.

Ciência Rural, v.37, n.4, jul-ago, 2007. 
Tabela 2 - Descrição e comparação da idade de óbito em cães do município de São Paulo em função do porte.

\begin{tabular}{|c|c|c|}
\hline \multirow{2}{*}{ Porte } & \multicolumn{2}{|c|}{ Idade de óbito (meses) } \\
\hline & Mediana (IQR) & [quartil 1; quartil 3] \\
\hline Médio (n = 460) & $84,0(99,3)$ & {$[24,0 ; 123,3]^{\dagger}$} \\
\hline Gigante $(\mathrm{n}=127)$ & $67,2(86,8)$ & {$[21,2 ; 108,0]^{\dagger}$} \\
\hline Grande $(n=412)$ & $60,0(108,0)$ & {$[12,0 ; 120,0]^{\dagger \ddagger}$} \\
\hline Pequeno $(n=776)$ & $24,0(95,0)$ & {$[3,0 ; 98,0]$} \\
\hline Indeterminado $(\mathrm{n}=236)$ & $11,0(13,3)$ & {$[4,0 ; 17,3]^{\dagger * \#}$} \\
\hline
\end{tabular}

IQR: intervalo interquartil.

* indica diferença estatisticamente significante, $P=0,0001$; em relação ao porte gigante.

$\dagger$ indica diferença estatisticamente significante, $P=0,0001$; em relação ao porte pequeno.

¥ indica diferença estatisticamente significante, $P=0,0001$; em relação ao porte médio.

\# indica diferença estatisticamente significante, $P=0,0001$; em relação ao porte grande.

Ainda com relação às causas de morte, notou-se que os traumatismos foram a terceira causa mais importante de morte dos animais, bem próximo das neoplasias (Tabela 3). Mortes por traumatismos também foram identificadas em outros trabalhos (ANDERSEN \& ROSENBLATT, 1965; BONNETT, 1997; HAYASHIDANI et al., 1998), porém com taxas de prevalência menores que as observadas neste levantamento. Neste sentido, parece prudente que os médicos veterinários orientem os proprietários de animais quanto à adoção de medidas de segurança que minimizem tais riscos, como o uso de guias e coleiras durante os passeios com a devida assistência de uma pessoa responsável.
Na tabela 3 está descrita a idade mediana de óbito em função da sua causa. Pode-se verificar que os cães que morreram por senilidade (causas naturais) apresentaram tempo mediano de vida (144 meses) significativamente superior a todas as outras causa de óbito. Os cães que morreram devido a neoplasias apresentaram tempo mediano de vida (84 meses) significativamente maior que os cães que morreram devido a doenças congênito-hereditárias, causas indeterminadas, doenças infecciosas e por intoxicação. Os cães acometidos por problemas cardiocirculatórios apresentaram tempo mediano de vida (73 meses) significativamente superior ao dos cães que faleceram devido a doenças congênito-hereditárias, infecciosas

Tabela 3 - Descrição e comparação da idade de óbito em cães do município de São Paulo em função da causa de óbito e de sua freqüência.

\begin{tabular}{|c|c|c|c|}
\hline \multirow{2}{*}{ Causa de óbito } & \multirow{2}{*}{ Freqüência (\%) } & \multicolumn{2}{|c|}{ Idade de óbito (meses) } \\
\hline & & Mediana (IQR) & [quartil 1; quartil 3] \\
\hline Senilidade & $112(5,57)$ & $144,0(48,0)$ & {$[120,0 ; 168,0]$} \\
\hline Neoplásica & $267(13,28)$ & $84,0(118,0)$ & {$[14,0 ; 132,0]^{\dagger \neq a \S \$}$} \\
\hline Cardiocirculatória & $79(3,93)$ & $73,0(126,0)$ & {$[2,0 ; 138,0]^{\$}$} \\
\hline Metabólica & $199(9,90)$ & $49,0(106,0)$ & {$[10,0 ; 116,0]^{\text {tas }}$} \\
\hline Traumática & $263(13,08)$ & $48,0(83,6)$ & {$[14,0 ; 97,6]^{\text {†a\#\$ }}$} \\
\hline Intoxicação & $100(4,97)$ & $36,0(72,0)$ & {$[12,0 ; 84,0]^{+\infty \$}$} \\
\hline Ortopédica & $51(2,54)$ & $36,0(96,0)$ & {$[8,0 ; 104,0]^{\dagger \$}$} \\
\hline Indeterminada & $125(6,22)$ & $24,0(90,0)$ & {$[8,0 ; 98,0]^{\dagger \$}$} \\
\hline Neurológica & $49(2,44)$ & $20,4(147,0)$ & {$[9,0 ; 156,0]^{\dagger \$}$} \\
\hline Infecciosa & $706(35,11)$ & $12,0(81,0)$ & {$[3,0 ; 84,0]^{* \$}$} \\
\hline Parasitária & $41(2,04)$ & $8,0(94,0)$ & {$[2,0 ; 96,0]^{* \# \$}$} \\
\hline Congênito-hereditária & $19(0,94)$ & $5,0(15,4)$ & {$[1,1 ; 16,5]^{* \$}$} \\
\hline
\end{tabular}

IQR: intervalo interquartil.

* indica diferença estatisticamente significante, $P=0,05$; em relação a doenças cardiocirculatórias.

† indica diferença estatisticamente significante, $P=0,05$; em relação a doenças congênito-hereditárias.

‡ indica diferença estatisticamente significante, $P=0,05$; em relação a doenças indeterminadas.

$\$$ indica diferença estatisticamente significante, $P=0,05$; em relação ao estado senil.

a indica diferença estatisticamente significante, $P=0,05$; em relação a doenças infecciosas.

$\S$ indica diferença estatisticamente significante, $P=0,05$; em relação a intoxicação.

\# indica diferença estatisticamente significante, $P=0,05$; em relação a doenças neoplásicas.

Ciência Rural, v.37, n.4, jul-ago, 2007. 
e parasitárias. As mortes por causas naturais, problemas metabólicos e circulatórios ocorreram em animais com idade mediana mais avançada, assim como foi observado por outros autores (BONNETT, 1997; HAYASHIDANI et al., 1998).

No Brasil, há uma carência muito grande de informações quanto à longevidade dos animais de estimação, portanto, os resultados obtidos na presente investigação são de grande importância, uma vez que descrevem a situação atual da população canina e podem contribuir para futuras comparações. Esses achados também podem orientar na adoção de medidas para prevenir o surgimento de doenças ou que promovam a saúde da população canina em geral.

\section{CONCLUSÕES}

Este estudo permite concluir que a taxa média de sobrevivência de cães no município de São Paulo foi de 36 meses de idade. Os animais de portes médio, grande e gigante tiveram maior longevidade que os cães de pequeno porte. Não houve diferença na taxa de sobrevivência dos animais com relação ao fato de apresentarem ou não raça definida. As fêmeas viveram mais que os machos e os animais castrados sobreviveram mais que os não-castrados. As doenças infecciosas constituíram a principal causa de morte, seguidas das neoplasias e dos traumatismos.

\section{REFERÊNCIAS}

ANDERSEN, A.C.; ROSENBLATT, L.S. Survival of Beagles under natural and laboratory conditions. Experimental Gerontology, v.1, n.2, p.193-199, 1965.

BERZINS, M.A.V.S. Velhos, cães e gatos: interpretação de uma relação. 2000. 132f. Dissertação (Mestrado em Gerontologia) - Curso de Pós-graduação em Gerontologia, Pontifícia Universidade Católica de São Paulo.

BONNETT, B.N. et al. Mortality in insured Swedish dogs: rates and causes of death in various breeds. Veterinary Record, v.141, n.12, p.40-44, 1997.
BRONSON, R.T. Variation in age at death of dogs of different sexes and breeds. American Journal of Veterinary Research, v.43, n.1, p.2057-2059, 1982.

DEEB, B.J.; WOLF, N.S. Studying longevity and morbidity in giant and small breeds of dogs. Veterinary Medicine, v.89, (suppl.7), p.702-713, 1994.

FRIES, J.F. ; CRAPO, L.M. Vitality and aging implications. San Francisco: W.H. Freeman, 1981. 366p.

HAYASHIDANI, H. et al. Epidemiological studies on the expectation of life for dogs computed from animal cemetery records. Japanese Journal of Veterinary Science, v.50, n.5, p.1003-1008, 1998.

HAYFLICK, L. The cell biology of aging. Clinics in Geriatric Medicine v.1, n.1, p.15, 1985.

GOLDSTON, R.T.; HOSKINS, J.D. Geriatria e gerontologia do cão e do gato. São Paulo: Roca, 1999. 551p.

MICHELL, A.R. Longevity of british breeds of dogs and its relationships with sex, size, cardiovascular variables and disease. Veterinary Record, v.145, n.27, p.625-629, 1999.

PAPALÉO NETTO, M. Gerontologia - a velhice e o envelhecimento em visão globalizada. São Paulo: Atheneu, 2002. 135p.

PARANHOS, N.T. Estudo das populações canina e felina em domicílio, município de São Paulo, 2001. 2002. $156 f$. Dissertação (Mestrado em Saúde Pública) - Curso de Pósgraduação em Saúde Pública, Universidade de São Paulo.

PATRONEK, G.J. et al. Comparative longevity of pet dogs and humans: implications for gerontology research. Journal of Gerontology: Biological Science A, v.52, n.3, p.171-178, 1997.

PROSCHOWSKY, H.F. et al. Mortality of purebreed and mixedbreed dogs in Denmark. Preventive Veterinary Medicine, v.58, n.2, p.63-74, 2003.

WALFORD, R.L. The extension of maximum life span. Clinics in Geriatric Medicine, v.1, n.2, p.29, 1985.

WONG, S.K. et al. Healthy pets, healthy people. Journal of the American Veterinary Medical Association, v.215, n.6, p.335-338, 1999. 